\title{
PENGELOLAAN PELATIHAN PEMBUATAN PUPUK ORGANIK BAGI REMAJA PUTUS SEKOLAH DI PAMPUNG PLUMBON KARANGANYAR
}

\author{
Galuh Ajeng Shintara dan Sofyan Anif \\ Magister Administrasi Pendidikan Sekolah Pascasarjana \\ Universitas Muhammadiyah Surakarta \\ Galuhparamore@yahoo.co.id
}

\begin{abstract}
The purpose of this study is to describe the planning and implementation of training dropout, describes the factors driving and the problems encountered in the training dropout organic fertilizer, and describe the impact of the activity of teenagers dropping out of school in the training of organic fertilizer in the hamlet Pampung. The approach used in this study is qualitative descriptive. Data collection was conducted using interview, observation and documentation. From the results, the data include: (1). Chemical fertilizer or inorganic fertilizer was shown to lower the quality / damage to the soil; (2). Limousine cow manure waste not managed optimally in Hamlet Pampung; (3). Dropout yet have the ability and knowledge of how to treat the sewage Limousine cow waste into something more useful; and (4). Dropout and farmers are very enthusiastic about the training activities making organic fertilizer from cow dung material Limousine. In order for this training management objectives can be achieved by optimum, then several things that must be considered are: (1). Make this activity as an activity that has a follow-up plan to the marketing process organic fertilizer; (2). Structuring membership consists primarily Pampung hamlet residents, it is to facilitate the coordination of activities in the future; (3). The need for cooperation in the management of organic fertilizers to be marketed properly and smoothly, so it can become a useful citizen entrepreneurs.
\end{abstract}

Keywords: Dropout, organic fertilizer, cow manure.

\begin{abstract}
ABSTRAK
Tujuan dari penelitian ini adalah mendeskripsikan perencanaan dan pelaksanaan pelatihan remaja putus sekolah, mendeskripsikan faktor-faktor pendorong dan masalah yang dihadapi remaja putus sekolah dalam pelatihan pembuatan pupuk organik, dan mendeskripsikan dampak keaktifan remaja putus sekolah dalam pelatihan pembuatan pupuk organik di dukuh Pampung. Pendekatan yang digunakan dalam penelitian ini adalah kualitatif yang bersifat deskriptif. Pengumpulan data yang dilaksanakan dengan menggunakan teknik wawancara, observasi dan dokumentasi. Dari hasil penelitian didapatkan data berupa: (1). Pupuk kimia atau pupuk non organik
\end{abstract}


memang terbukti dapat menurunkan kualitas/merusak tanah; (2). Limbah kotoran sapi Limosin belum dikelola secara maksimal di Dukuh Pampung; (3). Remaja putus sekolah belum memiliki kemampuan dan pengetahuan cara mengolah kotoran limbah sapi Limosin menjadi sesuatu yang lebih bermanfaat; dan (4). Remaja putus sekolah dan kelompok tani sangat antusias dengan kegiatan pelatihan pembuatan pupuk organik dari bahan kotoran sapi Limosin. Agar tujuan pengelolaan pelatihan ini dapat dicapai dengan optimal, maka beberapa hal yang harus menjadi pertimbangan yaitu: (1). Menjadikan kegiatan ini sebagai kegiatan yang memiliki rencana tindak lanjut hingga proses pemasaran pupuk organik; (2). Menyusun struktur keanggotaan yang utamanya beranggotakan warga dukuh Pampung, hal ini untuk mempermudah koordinasi kegiatan kedepannya; (3). Perlu adanya kerjasama dalam pengelolaan pupuk organik hingga dapat dipasarkan dengan baik dan lancar, sehingga dapat menjadi wirausaha warga yang bermanfaat.

Kata Kunci: Remaja putus sekolah, pupuk organik, kotoran sapi.

\section{PENDAHULUAN}

Proses pelatihan menghasilkan kompetensi remaja dalam melaksanakan dan mengelola pengembangan secara mandiri. Kompetensi mengandung dua unsur utama yaitu tanggung jawab dan kemampuan. Remaja putus sekolah menyadari bahwa proses perubahan untuk meningkatkan kondisi kehidupan atau untuk meningkatkan kesejahteraan adalah merupakan tanggung jawab mereka sendiri.

Sehubungan dengan permasalahan di atas, disadari bahwa dalam setiap masyarakat sebenarnya tersedia resources atau sumber daya yang merupakan potensi dalam rangka pemenuhan kebutuhan. Sebagai potensi resource atau sumber daya memang baru mengandung kemungkinan-kemungkinan untuk meningkatkan kesejahteraan, sehingga pengaruh resource tidak bersifat otomatis. Dan perlu adanya pengembangan dan pengelolaan lebih lanjut.

Pengelolaan pelatihan remaja putus sekolah sendiri mempunyai tujuan untuk memberikan wawasan dan keterampilan kepada remaja putus sekolah tentang pengelolaan limbah kotoran sapi Limosin di dukuh Pampung. Dari mulai proses pengolahan limbah menjadi pupuk organik sampai pemasaran semua dilakukan oleh peneliti beserta para remaja putus sekolah dan dibantu oleh anggota kelompok tani setempat, hal ini dilakukan untuk mengajarkan kepada para remaja putus sekolah bagaimana caranya dalam mengelola usaha pemberdayaan masyarakat ini agar mereka dapat meneruskan usaha ini hingga nantiya dapat berjalan meski tanpa bimbingan peneliti.

Peneliti bersama warga masyarakat dukuh Pampung bersepakat untuk membuat pupuk organik dengan sistem yang telah diajarkan oleh para ahli dalam bidang pertanian organik, dan hasil pupuk organik tersebut akan digunakan oleh warga sebagai pengganti pupuk kimia/ pupuk non organik yang dapat merusak tanah dan selama ini masih digunakan oleh petani sayur di dukuh Pampung.

Pemanfaatan limbah peternakan (kotoran ternak) merupakan salah satu alternatif yang sangat tepat untuk mengatasi kelangkaan dan naiknya harga pupuk. Pemanfaatan kotoran 
ternak sebagai pupuk sudah dilakukan petani secara optimal di daerah-daerah sentra produk sayuran. Sayangnya masih ada kotoran ternak tertumpuk di sekitar kandang dan belum banyak dimanfaatkan sebagai sumber pupuk. Keluhan petani saat terjadi kelangkaan atau mahalnya harga pupuk non organik (kimia) dapat diatasi dengan menggiatkan kembali pembuatan dan pemanfaatan pupuk kompos.

\section{METODE}

Jenis penelitian berdasarkan pendekatannya adalah penelitian kualitatif. Metode penelitian kualitatif adalah metode penelitian yang berlandaskan pada filsafat postpositivisme, digunakan untuk meneliti pada kondisi obyek yang alamiah. Hasil penelitian kualitatif lebih menekankan makna dari pada generalisasi.

Pada penelitian kualitatif peneliti dituntut agar dapat menggali data berdasarkan apa yang diucapkan, dirasakan, dan dilakukan oleh sumber data. Guna melakukan penelitian melalui pendekatan deskriptif, maka peneliti harus memaparkan, menjelaskan serta menggambarkan data yang telah diperoleh oleh peneliti melalui wawancara mendalam yang dilakukan dengan para informan. Analisis data dilakukan sejak sebelum memasuki lapangan, selama di lapangan, dan setelah selesai kegiatan di lapangan.

Subyek penelitian ini adalah para remaja putus sekolah, pemilik sapi Limosin di Dukuh Pampung, dan kelompok tani. Dari ketiga subyek ini diharapkan dapat terjalin hubungan yang saling menguntungkan atau simbiosis mutualisme.

Teknik pengumpulan data merupakan langkah yang paling utama dalam penelitian, karena tujuan utama dari penelitian adalah mendapatkan data. Tanpa mengetahui teknik pengumpulan data, maka peneliti tidak akan mendapatkan data yang memenuhi standart ditetapkan. Teknik pengumpulan data yang digunakan dalam penelitan ini adalah: wawancara, observasi dan dokumentasi.

\section{HASIL DAN PEMBAHASAN}

1. Perencanaan, pelaksanaan dan penutupan pelatihan remaja putus sekolah dalam pembuatan pupuk organik di Dukuh Pampung, Desa Plumbon, Kecamatan Tawangmangu, Kabupaten Karanganyar.

\section{a. Tahap Perencanaan}

Tahap perencanaan yang dilakukan terkait dengan beberapa kegiatan yaitu: penetapan waktu dan tempat kegiatan, jumlah peserta, konsumsi peserta pelatihan, persiapan alat dan bahan yang akan digunakan dalam penelitian, pembuatan undangan, materi, jumlah materi dalam satuan mata pelatihan, metode penyampaian materi, jumlah anggaran yang dibutuhkan.

Materi dalam pelatihan bagi remaja putus sekolah di Dukuh Pampung meliputi: Uji Tekstur Tanah, Uji Daya Kapiler, Uji KMA, Uji Aerasi, Biota Tanah, Pembuatan MOL (Mikro Organisme Lokal) dan Pembuatan Pupuk Organik.

Alokasi dana kegiatan akan digunakan untuk memenuhi bahan habis pakai yang akan digunakan berupa kertas buram, kertas HVS-kwarto, alat tulis lengkap (bolpoin, pensil, spidol), amplop besar/kecil, stapels dan isi, serta banner. Dan media praktek pembuatan pupuk organik yaitu: kotoran sapi 2 ton, gula pasir $1 \mathrm{Kg}$, jerami padi 5 ikat, 
limbah sayuran, serbuk gergaji, abu Sekam, kalsit/kapur, dan tetes tebu. Peralatan yang akan dipakai dalam pelatihan yaitu: sekop, cangkul, botol aqua bekas, solder, gunting, sekop kecil, galian tanah, bambu, peralatan lapangan, sarung tangan dan sepatu boot.

Biaya yang harus difikirkan dengan seksama yaitu pertemuan konsultatif dan insentif pakar meliputi konsultasi awal peneliti dengan narasumber, konsultasi persiapan penelitian, mendatangkan narasumber. Sedangkan analisis konsumsi, transportasi alat dan bahan meliputi: Biaya transportasi alat dan bahan, Snack \& kopi selama empat hari. b. Tahap Pelaksanaan.

Hasil praktek hari pertama remaja putus sekolah dan kelompok tani Dukuh Pampung adalah: Perbedaan kondisi tanah dahulu dengan kondisi tanah sekarang. Karena tidak menggunakan bahan kimia dalam sistem pertanian, maka keadaan tanah dulu lebih subur, kuat menahan air, berwarna hitam, banyak cacing dan belut. Sedangkan kondisi tanah sekarang gersang, tandus, dangkal, keras, sulit diolah, dan cepat kering.

Berikut merupakan hasil praktek hari ke-2, yaitu: Uji Tekstur Tanah, Uji Daya Kapiler Tanah, Uji Kemampuan Tanah Mengikat Air (KMA), dan Uji Aerasi Tanah.

Hasil uji tekstur tanah

\begin{tabular}{|c|c|c|c|c|c|c|c|c|c|}
\hline \multirow{2}{*}{ No } & \multirow{2}{*}{ Jenis tanah } & \multicolumn{3}{|c|}{ Komposisi (cm) } & \multirow{2}{*}{$\begin{array}{c}\text { Warna } \\
\text { air }\end{array}$} & \multicolumn{3}{|c|}{ Prosentase (\%) } & \multirow{2}{*}{ Kesimpulan } \\
\hline & & Pasir & Debu & Liat & & Pasir & Debu & Liat & \\
\hline 1 & Tanah kebun & $7 \mathrm{~cm}$ & $2 \mathrm{~cm}$ & $10 \mathrm{~cm}$ & $\begin{array}{c}\text { Agak } \\
\text { bening }\end{array}$ & 35 & 15 & 50 & $\begin{array}{cr}\text { - Tanah kebun } \\
\text { teksturnya }\end{array}$ \\
\hline 2 & TK + Pasir & $5 \mathrm{~cm}$ & $7,5 \mathrm{~cm}$ & $6,5 \mathrm{~cm}$ & Bening & 23 & 44 & 33 & pasir berdebu \\
\hline 3 & $\mathrm{TK}+\mathrm{BO}$ & - & - & - & Keruh & - & - & - & $\begin{array}{l}-\mathrm{TS}+\mathrm{BO} \text { di } \\
\text { dominasi oleh } \\
\text { BO }\end{array}$ \\
\hline
\end{tabular}

Hasil Uji Daya Kapiler Tanah

\begin{tabular}{|c|c|c|c|c|c|c|c|c|c|}
\hline \multirow[b]{2}{*}{ No } & \multirow[b]{2}{*}{$\begin{array}{l}\text { Jenis } \\
\text { tanah }\end{array}$} & \multirow{2}{*}{$\begin{array}{c}\text { Jml air } \\
\text { yang } \\
\text { dituang }\end{array}$} & \multicolumn{5}{|c|}{ Kecepatan air naik (cm) } & \multirow{2}{*}{$\begin{array}{l}\text { Sisa air di } \\
\text { mangkuk } \\
\text { (cc) }\end{array}$} & \multirow[b]{2}{*}{ Kesimpulan } \\
\hline & & & $15^{\prime}$ & 30 ’ & $45^{\prime}$ & $60^{\prime}$ & $\begin{array}{c}\text { Air sampai } \\
\text { dipermukaan }\end{array}$ & & \\
\hline \multirow[b]{2}{*}{1} & Tanah & & & & & & 1 jam & & \multirow{4}{*}{$\begin{array}{l}\text { TK + BO lebih } \\
\text { mampu menahan } \\
\text { air di banding } \\
\text { TK/ TK + Pasir }\end{array}$} \\
\hline & Kebun & 500 сс & 11 & 12 & 14 & 15,5 & 20 menit & & \\
\hline 2 & $\begin{array}{l}\text { TK+ } \\
\text { Pasir }\end{array}$ & 500 сс & 12 & 13,5 & 14,7 & 15,7 & $\begin{array}{c}1 \text { jam } \\
45 \text { menit }\end{array}$ & & \\
\hline 3 & $\mathrm{TK}+\mathrm{BO}$ & 500 сс & 5 & 5,5 & 6 & 6 & - & & \\
\hline
\end{tabular}


Hasil Uji Kemampuan Tanah Mengikat Air (KMA)

\begin{tabular}{cccccccc}
\hline No & Jenis Tanah & $\begin{array}{c}\text { Jml Air Yg } \\
\text { Dituang (cc) }\end{array}$ & $\begin{array}{c}\text { Kecepatan air } \\
\text { turun(menit) }\end{array}$ & $\begin{array}{c}\text { Jml air } \\
\text { yg turun } \\
\text { cc }\end{array}$ & $\begin{array}{c}\text { Jml air yg } \\
\text { terikat cc }\end{array}$ & $\begin{array}{c}\text { Warna } \\
\text { air }\end{array}$ & Kesimpulan \\
\hline 1 & Tanah Kebun & 500 & 2 menit & 312,5 & 187,5 & Bening & \\
2 & TK + Pasir & 500 & 1,20 menit & 375 & 125 & $\begin{array}{c}\text { Agak } \\
\text { keruh }\end{array}$ & $\begin{array}{c}\text { baik mengikat } \\
\text { air dari yg lain }\end{array}$ \\
3 & TK + BO & 500 & 1 menit & 93,75 & 406,25 & Coklat & \\
\hline
\end{tabular}

Hasil Uji Aerasi Tanah

\begin{tabular}{cccccc}
\hline No Jenis Tanah & $\begin{array}{c}\text { Kecepatan } \\
\text { udara turun }\end{array}$ & Kondisi gelembung & $\begin{array}{c}\text { Lamanya } \\
\text { balon } \\
\text { kempes }\end{array}$ & Kesimpulan \\
\hline 1 & Tanah Kebun & Sangan lambat & Sedikit dan kecil2 & 60,5 menit & TK+BO sirkulasi udara \\
2 & TK+ Pasir & Lambat & Sedikit dan sedang & 7 menit & $\begin{array}{c}\text { dalam tanah lebih baik di } \\
\text { banding TK/TK+Pasir }\end{array}$ \\
\hline
\end{tabular}

Catatan:

TK : Tanah kebun

BO : Bahan Organik.

Kegiatan hari ketiga adalah pembuatan MOL (Mikro Organisme Lokal), dan pembuatan pupuk organik. MOL dibuat dari berbagai bahan yang berada di sekitar kita seperti bonggol pisang, keong, terasi, pepaya, air kelapa, rebung, dan limbah dapur. Bahan-bahan ini dikombinasikan dengan bahan lain sehingga diperoleh mikroorganisme yang banyak. Semakin banyak mikroorganisme pada bahan, proses dekomposisi bahan organik atau pengomposanakan semakin cepat. Fungsi MOL sebagai bahan utama untuk mempercepat pengomposan bahan organik menjadi kompos.

Hal ini serupa dengan pernyataan dari Wayudi, (2015) yaitu “dalam pembuatan MOL (Mikro Organisme Lokal) di Dukuh Pampung akan menggunakan bahan dan alat yang mudah ditemui di lingkungan sekitar, yaitu bonggol pisang, terasi, buah-buahan, air kelapa, rebung, dan limbah dapur”.

Kegiatan hari keempat ialah proses pengamatan Biota Tanah dengan cara menimbang bahan organik yang lembab sebanyak $1 \mathrm{Kg}$, kemudian mengamati makhluk hidup yang di dalam tanah. Setelah mengadakan pengamatan, para peserta menemukan jenis mahluk hidup sebagai berikut: Celengan 39 ekor, Semut 2 ekor, Kala jengking 2 ekor, Laba- laba 4 ekor, Capit 2 ekor, Kumbang kubah 1 ekor, Colleombola 4 ekor, Keboan 1 ekor, Set 1 ekor, dan Cecopet 1 ekor. Jadi total jumlah makhluk hidup adalah 57 ekor.

Berdasarkan pengamatan Biota Tanah, maka didapat kesimpulan: Mengetahui, mengerti dan memahami bahwa didalam bahan organik terdapat berbagai jenis makhluk hidup, memahami nilai keberlangsungan sebuah kehidupan di dalam tanah mengandung 
bahan organik, makhluk hidup yang ada didalam tanah dapat memberikan keseimbangan di ekosistem serta bahwa makhluk hidup itu diciptakan untuk memberikan manfaat.

Hasil temuan penelitian ini sesuai dengan teori Suntoro Wongso Atmojo (2003) yang menyatakan bahwa beberapa mikroorganisme yang beperan dalam dekomposisi bahan organik adalah fungi, bakteri dan aktinomisetes. Di samping mikroorganisme tanah, fauna tanah juga berperan dalam dekomposi bahan organik antara lain yang tergolong dalam protozoa, nematoda, Collembola, dan cacing tanah.

\section{c. Tahap Penutupan}

Kegiatan yang dilakukan selama penutupan acara adalah sebagai berikut: ucapan penutupan dan permohonan ma'af dari peneliti dan para ahli pertanian organik, acara selamatan nasi tumpeng yang diberikan oleh para peserta pelatihan kepada peneliti dan para ahli pertanian organik, serta pemberian laporan kegiatan pelatihan dari Paguyuban SRI Organik Ngawi kepada peneliti.

Pelatihan ini diharapkan membangun sikap dan pemikiran para remaja putus sekolah untuk lebih mandiri, lebih kreatif dalam mengolah sumber daya atau limbah yang banyak tersedia di sekitar mereka. Dan menjadikan itu potensi untuk mengembangkan menjadi wirausaha yang dapat mereka andalkan.

Hasil temuan penelitian ini sesuai dengan hasil penelitian terdahulu Moerdiyanto, (2006) yang menyatakan bahwa usaha pelatihan guna pemberdayaan dalam bentuk pemberian pendidikan kewirausahaan ini diharapkan agar remaja putus sekolah secara mandiri mampu keluar dari kemiskinan, keterbelakangan, dan kebodohannya. Pemberdayaan ini dimaksudkan agar masyarakat lebih bersikap kreatif, inovatif menggali sumber daya dan sumber dana yang ada di lingkungannya guna meningkatkan produktivitas kerja mereka untuk membangun ekonomi keluarga secara swadaya.

2. Faktor-faktor pendorong dan masalah yang dihadapi remaja putus sekolah dalam pelatihan pembuatan pupuk organik di Dukuh Pampung, Desa Plumbon, Kecamatan Tawangmangu, Kabupaten Karanganyar.

Motivasi belajar, bahan yang digunakan terdapat di lingkungan sekitar dan alat yang dipakai sebagian besar adalah bekas pakai/limbah juga menjadi faktor pendorong bagi para peserta pelatihan. Sehingga pelatihan ini tidak membutuhkan biaya yang besar untuk pembelian alat dan bahan yang akan digunakan dalam praktek-praktek materi pertanian organik. Selain itu, bahasa para ahli pertanian organik yang mudah dipahami peserta pelatihan. Dan sebelum praktek pembuatan pupuk organik, terlebih dahulu diberikan praktek-praktek mengenai air, tanah, mikro organik, nutrisi tanah, dll. Ini dilakukan agar para peserta pelatihan mengerti komponen dasar dari pertanian organik sebelum akhirnya mampu membuat pupuk organik. Hal ini menambah rasa ingin tahu dari peserta pelatihan.

Hasil temuan penelitian ini sesuai dengan hasil penelitian terdahulu Nunik dan Djukri, (2010) menyatakan bahwa "Motivasi belajar merupakan satu faktor yang internal yang sangat mempengaruhi prestasi belajar. Hasil dari pembelajaran adalah perubahan pola pikir, tingkah laku sebagai penguatan untuk mencapai tujuan tertentu di dalam hidupnya”.

Penyampaian materi dari ahli pertanian organik kepada peserta pelatihan yang berbeda logat, hal ini disebabkan peneliti dan para ahli pertanian organik berasal dari Jawa Timur yang 
memiliki logat lebih tegas dan “ceplas ceplos”, sedangkan tempat penelitian berada di Jawa Tengah yang memiliki logat lebih halus. Meskipun perbedaan logat ini tidak menyebabkan masalah yang berkepanjangan namun cukup membuat peserta pelatihan kaget, setelah para ahli pertanian organik menyadari hal ini mereka pun dapat menyelesaikan kendala ini dengan candaan dan gurauan yang menambah ceria sepanjang pelatihan berlangsung.

3. Dampak keaktifan remaja putus sekolah dalam pelatihan pembuatan pupuk organik.

Pelatihan kepada para remaja putus sekolah sebagai cara pencegahan mereka untuk melakukan tindakan-tindakan yang dapat meresahkan masyarakat. Karena selama ini anak atau remaja yang terhenti dalam proses pendidikannya kebanyakan selalu tumbuh menjadi pengangguran dan gemar melakukan tindakan yang merugikan orang lain.

Hasil temuan penelitian ini sesuai dengan teori Agry Doly Purba, (2014) bahwa "Munculnya kenakalan anak remaja tanpa disadari dapat menimbulkan berbagai masalah antara lain : 1). Mengganggu ketertiban dan kenyamanan orang lain 2). Dapat membahayakan dirinya 3). Memberikan kondisi yang subur bagi tumbunya kriminalitas 4). Memberikan kesan yang kurang baik terhadap eksistensi bangsa dan negara. Kenakalan remaja tersebut meliputi perbuatan-perbuatan yang sering menimbulkan keresahan di lingkungan masyarakat, sekolah maupun keluarga”.

Pupuk organik dapat berupa pupuk cair dan padat, namun dalam pelatihan di Dukuh Pampung ini peneliti bersama para ahli pertaniamn organik lebih memilih membuat pupuk organik padat. Pupuk organik padat dipilih karena mempertimbangkan tempat pembuatan pupuk yang lebih praktis dan fleksibel menggunakan galian tanah dari pada menggunakan wadah-wadah dalam proses pembuatan pupuk cair.

Hasil temuan penelitian ini sesuai dengan teori Rudi Hartono dkk, (2010) yang berpendapat bahwa "Pupuk organik merupakan pupuk yang bisa berbentuk padat atau cair yang berasal dari tanaman dan atau pun hewan. Pupuk organik digunakan sebagai alternatif dari penggunaan pupuk kimia atau anorganik, karena selain dapat memperbaiki sifat fisik, kimia dan biologi tanah, pupuk organik secara ekonomis jauh lebih terjangkau dari pupuk anorganik, sehingga dapat mengurangi biaya produksi pertanian”. Ada juga pupuk organik berbentuk cair, yaitu cairan lumpur dari kotoran sapi yang telah melalui proses fermentasi dari digester dengan terlebih dahulu dipisahkan antara padatan dan cairan atau disebut dengan pengendapan.

\section{SIMPULAN}

Penelitian pengelolaan pelatihan pembuatan pupuk organik bagi remaja putus sekolah berlokasi di Dukuh Pampung, Desa Plumbon, Kecamatan Tawangmangu, Kabupaten Karanganyar, terutama ditujukan untuk remaja putus sekolah.

Setelah peserta pelatihan mengetahui dan memahami segala kebaikan dan manfaat dari pertanian organik, khususnya pupuk organik dari limbah kotoran sapi Limosin. Maka peneliti dan para ahli pertanian organik berharap para peserta pelatihan dapat membuat pupuk serupa secara berkesinambungan, dan jika memungkinkan adanya tindak lanjut hingga menjadi wirausaha warga Dukuh Pampung yang dapat diperjual belikan.

Tentunya penelitian ini memiliki beberapa faktor-faktor pendorong remaja putus sekolah dalam keberhasilan pelatihan, yaitu: bahan pembuatan pupuk organik yang digunakan 
terdapat di lingkungan sekitar, seperti limbah kotoran sapi, limbah buah dan sayuran, tetes tebu, serasah daun dan banyak lagi pemanfaatan limbah yang menjadi bahan pupuk organik; alat yang dipakai sebagian besar adalah bekas pakai/limbah; rasa semangat dan antusias peserta pelatihan, selama empat hari para peserta pelatihan ikut membantu mempersiapkan semua yang akan digunakan dalam pelatihan.

Sedangkan masalah yang dihadapi yaitu dalam hal penyampaian materi dari ahli pertanian organik kepada peserta pelatihan yang berbeda logat, hal ini disebabkan peneliti dan para ahli pertanian organik berasal dari Jawa Timur dan tempat penelitian berada di Jawa Tengah. Masyarakat Jawa Timur memiliki logat “ceplas ceplos”, jadi peneliti dan para ahli organik yang memang merupakan penduduk Jawa Timur harus menyesuaikan logat masyarakat Pampung yang berada di Jawa Tengah yang memiliki logat lebih halus.

Dampak keaktifan remaja putus sekolah mengarah kedua arah yang sangat berbeda, dapat berdampak positif jika mereka dibimbing dan diarahkan menjadi sumber daya manusia yang potensial jika memiliki skill dan keahlian. Namun akan berdampak sangat negatif jika mereka tidak dibimbing dan tidak mendapatkan perhatikan dari masyarakat dan pemerintah, mereka bisa melakukan tindak kriminalitas di kalangan masyarakat, mabuk-mabukan, mengikuti geng motor, mencuri, menjambret dan perilaku negatif yang lainnya.

\section{DAFTAR PUSTAKA}

Afrizal, 2014, Metode Penelitian Kualitatif, Jakarta: PT. Raja Grafindo Persada.

Anoop Yadav, dkk. 2013. Organic manure production from cow dung and biogas plant slurry by vermicomposting underfield conditions. Yadav et al. International Journal Of Recycling of Organic WasteinAgriculture. 2013, 2:21. http://www.ijrowa. com/content/2/1/21

Antoinette Sena Attigah, dkk. 2013. Growth And Yield Of Okra (AbelmoschussculentusL.) As Affected By Organic And Inorganic Fertilizers. ARPN Journal of Agricultural and Biological Science.C2006-2013 Asian Research Publishing Network (ARPN).VOL. 8, NO. 12, DECEMBER 2013 ISSN 1990-6145.

Bida. 2011. Cowdung: soil amendment agent for the sandy upland sugarcane ecology in Nigeria. Journal of Agricultural Technology 2011 Vol.7(2): 497-505. Available online http://www.ijat-aatsea.com. ISSN 1686-9141.

Djilani Ghemam dan Senoussi Mohammad dari fakultas Biologi, Universitas el-oued, Algeria. 2013. Influence of organic manure on the vegetative growth and tuber production of potato(solanumtuberosum L varspunta) in a Sahara desert regione.International Journal of Agriculture and Crop Sciences. Available online at www.ijagcs.com IJACS/2013/5-22/2724-2731 ISSN 2227-670X @2013 IJACS Journal

Endang Indrawati, Sri Harijati, dan Pepi Rospina Pertiwi, 2014, Permodelan pemberdayaan kelompok tani dalam penjaminan keberlanjutan usahatani pinggiran perkotaan. Journal International of Education. 9 Juni, Vol: 14.

Ghasem Salehabadi, Seyed Morteza Azimzadeh dan Maryam Tatary, 2014, Effect of organic fertilizers on cucumber( Cucumis sativus) yield, International Journal of Agriculture and Crop Sciences, JACS/2014/711/808-814 ISSN 2227-670X @2014 IJACS Journal. 
J. Tanimu, dkk. 2012. Effects of Cow Dung on the Growth and Development of Maize Crop. ISSN: 2276-7770 Impact Factor 2012 (UJRI): 0.7904 ICV 2012: 6.15

Mardikanto, 2009, Swadaya Masyarakat, Yogyakarta: Alfabeta.

Marsono \& Sigit Paulus, 2001, Pupuk Akar Jenis \& Aplikasi, Depok: PT. Penebar Swadaya

Mohammad Rezaul Hasan dan AHM Solaiman. 2012. Efficacy of organic and organic fertilizer on the growth of Brassica oleracea L. (Cabbage). International Journal of Agriculture and Crop Sciences. Available online at www.ijagcs.com . IJACS/2012/4-3/128-138. ISSN 2227-670X @2012 IJACS Journal

Moleong J. Lexy, 2012, Metodologi Penelitian Kualitatif, Bandung: PT. Remaja Rosdakarya

Norman Uphoff dari Cornell University. 2012. Empowerment of Farmers through ICT.Draft paper for ECOSOC Expert Group Meeting on Promoting Empowerment of People in AdvancingPoverty Eradication, Social Integration, and Decent Work for All, UN HQ, NYC, September 10-12, 2012.

Oladejo, dkk. 2015. Production of Bio Fertilizer From Rice Waste, Cow Dung and Timber Sawdust. International Journal of Chemical, Environmental \& Biological Sciences (IJCEBS) Volume 3, Issue 2 (2015) ISSN 2320-4087.

Rabia badar dkk, 2015, Effects of organic amendments in comparison with chemical fertilizer on cowpea growth. International Journal of Applied Research IJAR. 2015; 1(5): 66-71. ISSN: 2394-7500.

Salim Emil, 2013, Sukses Bisnis \& Beternak Sapi Potong, Yogyakarta: Lily Publiser.

Santrock John W. , 2007, Remaja, Yogyakarta: Gemilang jaya prees.

Siagian Sondang, 1993, Manajemen Sumber Daya Manusia, Surabaya: Gasindo Pustaka.

Simbarashe Govere, dkk dari Fakultas Lingkungan alam dan teknologi, Zimbabwe. 2011. The Nutrient Content of Organic Liquid Fertilizers in Zimbabwe. International Journal of Modern Engineering Research (IJMER) www.ijmer.com Vol.1, Issue1, pp- 196202 ISSN: 2249-6645.

Soetomo, 2012, Teori Perkembangan Manusia, Jakarta: Sinar Pustaka.

Solomon Wisdom, dkk dari Fakultas Ilmu Pengetahuan Biologi dari Universitas Abuja. 2012. The Comparative study of the effect of organic manure cow dung and anorganic fertilizer N.P.K on the growth rate of maize (Zea Mays L). International Research Journal of Agricultural Science and Soil Science (ISSN: 2251-0044) Vol. 2(12) pp. 516-519, December, 2012. Available online http://www.interesjournals.org/IRJAS. Copyright (C2012 International Research Journals.

Sulistiyani T. Ambar, 2003, Faktor Manajemen Sumber Daya Manusia, Bandung: Sinar Pustaka.

Suntoro Wongso Atmojo, 2003, Peranan Bahan Organikterhadap Kesuburan Tanah Dan Upaya Pengelolaannya, Sebelas Maret University Press: Surakarta 